\title{
Malay Language Mobile Learning System (MLMLS) using NFC Technology
}

\author{
Yahaya Garba Shawai ${ }^{1}$, Dr. Mohammed Amin Almaiah ${ }^{2}$ \\ ${ }^{1}$ Faculty of Informatics and Computing, Universiti Sultan Zainal Abidin Kuala Terengganu, Malaysia \\ ${ }^{2}$ Assistant Professor, Department of Computer Science, King Faisal University (KFU), Saudi Arabia
}

Received: 26 October 2017; Accepted: 19 December 2017; Published: 08 March 2018

\begin{abstract}
This paper proposes a portable learning framework that uses cell phones and Near Field Communication (NFC) innovation in which this application permits understudies to connect with genuine questions and get data from the labels that are put on the item by filtering the tag put on the article. These gimmicks empower the learning procedure at all over the place (pervasive learning) and enhance the viability of the learning methodology. In this paper, Mobile Application Development Lifecycle (MADLC) model was utilized to safeguard effective MLang framework conveyance. M-lang framework clients are required to utilize cell phones to advance the involvement in Malay Language learning.
\end{abstract}

Index Terms: Mobile Application Development Lifecycle (MADLC) Mobile learning lang system, Near Field Communication (NFC).

(C) 2018 Published by MECS Publisher. Selection and/or peer review under responsibility of the Research Association of Modern Education and Computer Science.

\section{Introduction}

A mobile phone is a portable device that can make and received calls over radio frequency that carrier, while the user is moving within a telephone service area. The radio frequency links and establishes a connection to the switching systems of a mobile phone operator, which provide access to the public switched telephone network. Most modern mobile telephone services uses a cellular telephones or cell phone. In addition to telephony, 2005-era mobile phones support a variety of other services, such as text messaging, MMS, Email, internet access, short-range wireless communication(infrared and Bluetooth) business application gaming, and digital photography, mobile phones which offer these and more general computing capabilities are referred to as smart phones.

* Corresponding author.

E-mail address: Shawaiyahayagarba76@gmail.com,malmaiah@kfu.edu.sa 
Mobile learning is a process of learning across a multiple context through social and content interaction using personal electronic devices. Regardless of the location, a user can learn anywhere [18,19]. [1] Reveals that teaching and learning can be supported with technological tool through e-learning as a result of rapid development of information and communication technology. [14] In a study, stated that e-learning is characterized as any utilization of web innovation to make instructive exercise and experience. Gradually; as a result of technological development, e-learning is extended to mobile-adapting. The advent of mobile learning in educational society was due to accessibility of mobile phones around the world. [11,20] Highlighted that mobile devices assisted language learning as a result technological advancement or enhancement

At present, more discovering possibilities and relationship based on the technological advancement are considered by using mobile phones in learning. These discoveries permit the use of mobile in learning by students in various learning environment. Likewise, Due to use of mobile in learning, students are motivated and considered it as effective way of learning as it create fun $[7,8]$. There are much innovation that are utilise in teaching learning process, the method applied where interested and intelligence that encourage mobile learning users. Mindstorm [9] and Nukotoys [10] illustrated mobile learning where the user's can be able to associate with articles embedded in a tag.

Ogata et al., [16] in a research improve the cell phone innovation in learning environment. The researcher introduces the pervasive learning by the students by which students can learn at any location provided that there mobile devices is with them. In this respect, it is believable that computerized Gadget is effective and ready to perform different capacities. $[4,15]$ asserted that using remote innovation is more useful on like using computers that are heavy to carry all the time. The use of cell phone within and outside the learning environment can improve learning procedures. Likewise portable learning (versatile learning) less expensive, adaptable, insignificant utilization of instrument and simple to utilize [12]. Due to stated facts, there is need to adopt mobile learning in all learning environment, utilizing such technological improvement can make learning more effective and create some fun to the students. NFC enhance learning kit(ELK) was built to give an intuitive learning process by utilizing cell phone.

\section{Related Works}

[3] Designed a game-based English tool via lyrics for mobile devices. Leaner can study using collocation word pair anytime and anywhere and combine their interest in music listening, with learning to promote studying and strengthen the effect of English learning. The researcher then further retrieved the features of the research by retrieving verb-noun collocation and makes question automatically, Secondly, to build a mobile learning environment for music and game. Furthermore social networks (YouTube and Face book) need to provide some method for heterogeneous system integrating and perhaps these methods can be used for grouping learner's common interest, collecting some useful public user data for analysis, and giving appropriate recommendation to individual or their friends

[6] Present a mobile2learn framework with the support of providing services and tool that facilitate language digital learning resources base on mobile assisted in an open source. The researcher presented the framework due to lack limitation of MALL as it does not pay attention in facilitating open access to their language learning resources and practices. The proposed framework receives the current learning technology determination and Web Mobile Content Standards, expecting to back the principle phases of a common place e-learning chain. The researcher review on mobile2learn framework indicates that; existing MALL assets can be re-utilized inside distinctive MALL Courses, while holding their open access by distinctive stages and framework. Existing MALL course formats can re-utilized inside diverse MALL courses tending in educating of a particular dialect.

Akinkuolie et al. [2] added to a client interface in light of portable learning for learning Chinese as a second dialect. QT SDK FRAMEWORK was utilized to add to the framework which chips away at cell phone. The advancement process and the framework construction modelling are clarified in the study. The framework comprises of three modules specifically, Translation, baffle, and test. The interpretation motor makes an 
interpretation of word from English to Chinese and from Chinese to English. The riddle was of three classes, English to Chinese, Pinyin to Chinese and Chinese to English. Riddle inquiry and client was capable to discover the comparing importance. The discoveries of the exploration indicated the vast majority of the worldwide students of National Chiao Tung University are involved in the analysis shows positive result in learning Chinese utilizing their cell phone. But there is requirement for more word inquiry riddle, multi decision question and making more combinations of intuitive learning choices for the framework

In this research was produced a framework for English dialect learning for students that utilizes cell phones and RFID [5]. The application comprises of cell phones, RFID per users, RFID labels and database. At the point when the RFID users meet any RFID tag, the RFID label data will be fetched from database remotely. At that point, the learner will begin searching for other RFID labels that are set a long way from one another. Guidelines for getting this RFID tag was shown in English and learner can utilize the "Help" catch on the product interface to hear back bearings or more data. Direction to meet the next RFID tag was given. At the point when all labels have been checked, learner will be offered time to enter a letter of all words as a secret key. The framework will record the slip that happened and the measure of time taken by understudies to enter the watchword. The application likewise permits educators to post inquiries and answers, the inquiries assist the researcher to update, modify and redesign the existing application.

Notwithstanding the utilization of NFC as supportive technology in creating learning applications, as such these innovation upgrades learning activities in a real world by utilizing cell phones. Riekki et al. [13] presented first NFC-based learning application that assisted kids in their learning activities. The application was tested in one kindergarten with 23(Three-to-five years of age kids) with their two teachers. The application was begun by touching the star symbol on little notice put on a divider in the kindergarten. The application has two modes. First, investigating mode which was begun by touching the star symbol alongside the fox character named as "Fox amusement". In this mode a straightforward movement was physically displayed on the screen of the mobile device. At the point when the name tag was touched the telephone says the name aloud. Second, was the honing mode which was begun by touching the star symbol alongside the rabbit character. The telephone presents a name a kid to touch the relating name tag. If no name tag was touched, the mobile device says the name Loud. There is need to build up a more developed learning application that uses the same innovation which will utilize system integration. Table 1 presents some of related works of previous studies on mobile learning systems and applications for learning language.

Table 1. Related Studies

\begin{tabular}{|l|l|l|}
\hline Literature & Objective of the study & Type of the mobile application \\
\hline $\begin{array}{l}\text { Chen-Chung Chi, Chin-Hwa } \\
\text { Kuo, Kuo-Yang Lin., (2012) }\end{array}$ & $\begin{array}{l}\text { Designed a game-based English tool via } \\
\text { lyrics for mobile devices. }\end{array}$ & $\begin{array}{l}\text { Mobile game application for English learning } \\
\text { tool }\end{array}$ \\
\hline $\begin{array}{l}\text { Demetrios G Sampson, } \\
\text { Panagiotis Zervas.(2012). }\end{array}$ & $\begin{array}{l}\text { Propose a mobile2learn framework with } \\
\text { the support of providing services and } \\
\text { tool that facilitate language digital } \\
\text { learning resources base on mobile } \\
\text { assisted in an open source. }\end{array}$ & Mobile2learn \\
\hline $\begin{array}{l}\text { Akinkuolie, Chai-Feng Len and } \\
\text { Shyan-Ming Yuan (2012) }\end{array}$ & $\begin{array}{l}\text { Develop a client interface in light of } \\
\text { portable learning for learning Chinese as } \\
\text { a second dialect. }\end{array}$ & $\begin{array}{l}\text { A cross-Platform mobile learning system using } \\
\text { QT SDK Framework }\end{array}$ \\
\hline
\end{tabular}

\section{Methodology}

\section{Design}

Mobile devices run different operating system (OS) such as Android, Windows mobile, Apple iOS and Blackberry RIM (Research in Motion). It is during the design activity the idea to develop the application that will run on Android OS come in to consideration. Vithani and Kumar [17] mentioned that existing application 
are search on different OS whether a similar application already exist. This will help in studying, comparing and documenting the functionalities of the existing and intended application. The application functionalities are designed and divided in to modules and identified the ones that can be done concurrently, Flowchart describing different parts and showing the flow of the application are drafted which will result in coming up with the whole architecture of the application.

\section{Development}

This is an alternate action in the improvement life cycle which includes coding the entire reported thought and results to an application's prototype. This includes the utilization of advancement programming such as Xamarin studio, android SDK and AVD manager. The modules that could be possible simultaneously are made an interpretation of into codes. The improvement movement includes coding the application client interfaces and its functionalities.

\section{Prototype}

Different versions are created at this stage. This involves combining the modules in to single file (Application) to produce a testing prototype.

\section{Testing}

In the process of creating M-Lang system, there is need to test its functionalities, whether it meets the prerequisite or not. The testing includes the utilization of android emulator from the AVD manager. Likewise M-Lang system was installed into genuine cell phones for testing. Different gadgets running distinctive android OS adaptation will be decided to test the application functionalities. Toward the end the researcher will carry out experiments so as to make required changes.

\section{Deployment}

Finally, after the last testing of the application there is requirement for different clients to get or download the application on their gadgets. Since the researcher added to an android application, it must be transferred and distribute to google play store for the clients to get the application.

\section{Result and Discussion}

The present research adopted mobile development lifecycle model in creating the Malay mobile language learning application. The developed application is named to be called M-Lang. The researcher uses NFC technology as a supporting tool that will support users in there learning environment. M-Lang displays some of the interface by touching NFC tag. At the end of each learning process, teachers usually carry out some test to investigate the performances of the students. The researcher provides Quiz Form in M-lang application to test student's performances, the form will be displayed when ever NFC tag is touched. The research was carried out at University Sultan Zainal Abidin Malaysia and University Malaysia Terengganu to test the usability of mobile learning by the international students. Analysis was carried out to evaluate the software based on the student's response. 


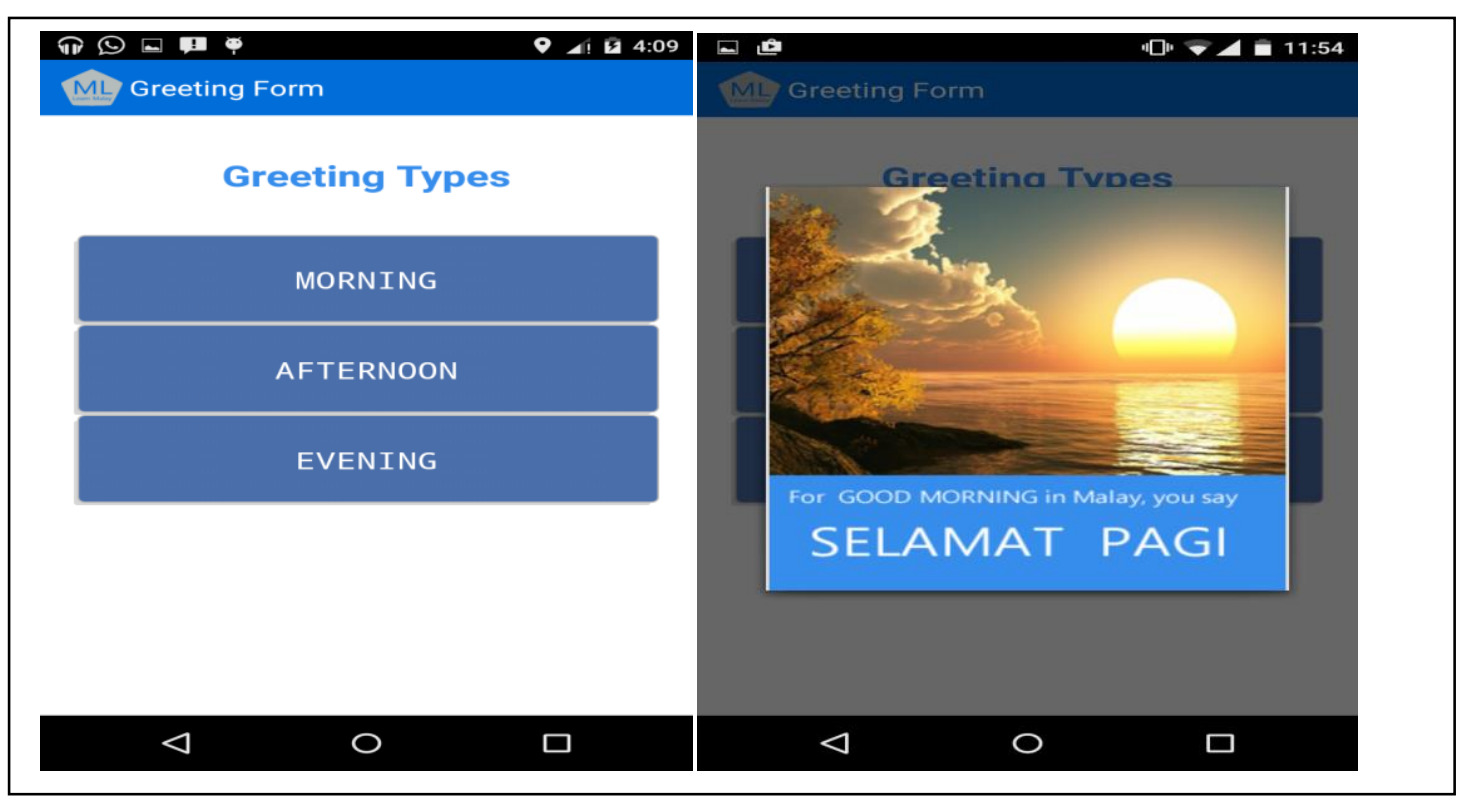

Fig.1. Greeting Type Layout

M-lang system was composed of four modules such as Counting, Greeting, Food type and Quiz module. Each module consist some dialogue boxes. Counting form enable user to count at a basic level. Fig 4.1 presents the greeting form and the respective morning greeting translation in Malay Language. Greeting form consists of three options where user of the system clicks on the required option to have the translated version of Malay morning, afternoon and evening greeting. Likewise food type menu was composed of the common food type taken for breakfast, lunch and dinner respectively. The system was interactive and game like, where user interacts with NFC tags to retrieve information in the database of the mobile device. The Quiz module was embedded in the system to test user learning experience, the quiz form contain objective questions which displays the scores.

\section{Conclusion}

Utilization of Mobile devices in the real world has expanded the capacity of cell phones to higher different bases such as battery innovation advances, enhanced information transfer system. The stated reason enhanced mobile learning (versatile learning) utilizing cell phones and NFC technology. As such, these technology permits clients to utilize cell phones to enhance their learning procedure. The use of NFC technology will encourage the teaching and learning procedures as it appear to be game like environment. In addition, the teaching and learning will be more intuitive that improves the viability of the learning process. The present research discussed the design and implementation of Malay Language learning tool known as M-Lang. The development was based on Mobile development Lifecycle Model, the researcher adopted the model and generate the M-Lang learning software that enable international students to learn Malay language. The system uses NFC technology supported device to achieve learning theories such as Ubiquitous and context aware. The use of NFC technology makes the system interesting and game like tool for learning as it requires touch on tag which makes it interactive with object directly.

M-Lang system can be used as a supplement for Malay language learning for international students in Malaysia. The future research for M-Lang system can be done by adding sound and video to the system and expand the application from basic Malay language learning to Higher Malay vocabularies by adding sentences 
construction. In genuine, individuals utilized the cell telephone and unite their telephone. This will give a possibility for individuals in light of the fact that they utilize their cell phone in Malay dialect learning anywhere. It will likewise help you take in the dialect at the essential level. This will help Malaysian to have method for correspondence with outsiders.

\section{Reference}

[1] Azadez Razaei,Neo Mai,Ahmad Pesaranghader. (2013). "Effectiveness of using English vocabulary mobile application in ESL's learning performance." International Conference on Informatics and Creative multimedia..Pg(114-118).

[2] Akinkuolie, Chai-Feng Len and Shyan-Ming Yuan (2012)."A cross-Platform mobile learning system using QT SDK Framework". $5^{\text {th }}$ Internatonal Conference on Genetic and Evolutionary Computing

[3] Chen-Chung Chi, Chin-Hwa Kuo, Kuo-Yang Lin., (2012). "A design of mobile Application for English learning." $7^{\text {th }}$ International Conference on Wireless,Mobile and Ubiquitous Technology in Education.

[4] Chen, Y.S., T.C. Kao, and J.P. Sheu. (2003). "A mobile learning system for scaffolding bird watching learning”. Journal of Computer Assisted Learning. 19( 3): Pp 255-398.

[5] David Tawei Ku, Chia-chi Chang. (2012). "Design and Development of Mobile English Learning Supporting System by Integrating RFID Technology for 4th grade Students".Journal of Convergence Information Technology(JCIT). 7(7): Pp 538-541

[6] Demetrios G Sampson, Panagiotis Zervas.(2012)."Open access to mobile assisted language learning supported by the mobile2learn framework".12 $2^{\text {th }}$ International Conference on Advanced Learning Technologies.Pg(441-445).

[7] Fisher, B., ed. Joyful learning in kindergarten. 1998, Portsmouth, NH: Heinemann.

[8] Heywood, P., Learning joyfully: An emotional and transformative experience. 2005.

[9] http://mindstorms.lego.com/en-us/Default.aspx. [cited 201220 July].

[10] http://www.nukotoys.com/. [cited 201220 July].

[11] Humez Korkmaz.(2010)"The Effective of Mobile Assisted Language Learning as a Supplementary Material for English Teaching Course Books". Masters Thesis, Bilkent University.

[12] Jones, V. and J.H. Jo. (2004). "Ubiquitous learning environment: An adaptive teaching system using ubiquitous technology", in Proceedings of the 21st ASCILITE (Australasian Society for Computers in Learning in Tertiary Education) Conference, R. Atkinson, et al., Editors: Perth, Australia: ASCILITE. Pp 468-474.

[13] Jukka Riekki, Marta Cortes, Marja Hytonen, Ivan Sanchez Riitta-Liisa Korkeamaki (2013)."Touching nametag with NFC phone; palyful approach to learning to read". Pp 228-242. Online book.

[14] Kostantinous Semetzidis.(2013). "Mobile Application Development to Enhanced Higher Education ".Masters Thesis, University of NewYork.

[15] Ogata, H. and Y. Yano. (2004). "CLUE: Computer supported ubiquitous learning environment for language learning". Transactions of Information Processing Society of Japan. 45(10): Pp 2354-2363.

[16] Ogata, H., R. Akamatsu, and Y. Yano. (2005). "TANGO: Computer supported vocabulary learning with RFID tags". Journal of Japanese Society for Information and Systems in Education. 22(1): Pp 30-35.

[17] Vithani, T., and Kumar, A. (2014)."Modelling the mobile application development lifecycle".Proceeding of the International MultiConference of Engineers and Computer Science. Pp 1-5.

[18] Yahaya Garba Shawai, Noor Maizura Mohamad Noor, Mustafa Mamat, Zabidin Salleh.(2015). "Gumsa Framework for the Development of Mobile Learning System of a Malay Language using Near Field Communication". Journal of Contemporary Engineering Science.8(14):Pp 623-640

[19] Almaiah, M. A., Jalil, M. A., \& Man, M. (2016). Extending the TAM to examine the effects of quality features on mobile learning acceptance. Journal of Computers in Education, 3(4), 453-485. 
[20] Almaiah, M. A., \& Man, M. (2016). Empirical investigation to explore factors that achieve high quality of mobile learning system based on students' perspectives. Engineering Science and Technology, an International Journal, 19(3), 1314-1320.

\section{Authors' Profiles}

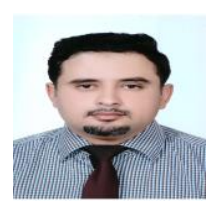

Mohammed Amin Almaiah obtained his PhD in Computer Science from Malaysia University Terengganu from Malaysia. MSc in Computer Information System from Middle East University (MEU) in 2011 from Jordan. He is now working as a Assistant Professor in the Department of CIS at King Faisal University, Saudi Arabia. His research interest: software engineering, mobile learning, and system quality.

Yahaya Garba Shawai obtained his master degree in Computer Science from Faculty of Informatics and Computing, Universiti Sultan Zainal Abidin Kuala Terengganu, Malaysia.

How to cite this paper: Yahaya Garba Shawai, Mohammed Amin Almaiah,"Malay Language Mobile Learning System (MLMLS) using NFC Technology", International Journal of Education and Management Engineering(IJEME), Vol.8, No.2, pp.1-7, 2018.DOI: 10.5815/ijeme.2018.02.01 